\title{
MICROBIAL COMMUNITY PROFILING OF DIGESTED SLUDGE FROM PILOT PLANT BIO-DIGESTER
}

\author{
ISMAFATINNABILAH ISMAIL, SHAHRUL ISMAILAND MOHAMED SHAHRIR MOHAMED \\ ZAHARI
}

Faculty of Ocean Engineering Technology and Informatics, Universiti Malaysia Terengganu, 21030 Kuala Nerus, Terengganu, Malaysia.

*Corresponding author: shahrul.ismail@umt.edu.my

http://doi.org/10.46754/umtjur.2021.07.006

\begin{abstract}
The production of biogas involves different microbial groups working in a synchronously and closely interactive manner. In Malaysia, biogas production from food waste is an encouraging alternative for sustainable energy production. Therefore, to better understand and optimize process, identification of the microbial community involved in anaerobic digestion (AD) is essential. The purpose of this study is to identify the microbial characteristics under different $\mathrm{AD}$ conditions to establish the links between microbial community structure and operational condition efficiency. The pilot plant bio-digester production performance will be determined by analysis of Chemical Oxygen Demand (COD) removal efficiency for 43 days. Next, when the performance of the digester has achieved an optimum level of removal efficiency, a sample of digested sludge will be taken for further analysis of microbial community profiling by undergo DNA extraction, amplifying DNA and Next Gene Sequencing (NGS) technology. The results show that the COD removal efficiency at an optimum level is $93 \%$, while the percentage of methane gas composition inside the digester is $69 \%$, indicating a very high efficiency for the digester. Thus, the lower the concentration of COD effluent, the higher the concentration of COD removal efficiency. Besides, an optimum an optimum level of COD removal efficiency indicates active microbial activities inside the bio-digester. Furthermore, the microbial community structure with operational conditions at various states of anaerobic digestion is summarizing. These findings are important as microbial characteristics of digested sludge is important to manage and optimize biogas production.
\end{abstract}

Keywords: Anaerobic digestion, biogas, bio-digester, chemical oxygen demand, digested sludge, microbial.

\section{Introduction}

As the world's population keeps growing, several initiatives have been discovered to establish resourceful methods of waste treatment while minimizing reliance on fossil fuels. The production of biogas is seen as an alternative source of renewable energy. Biogas generated by anaerobic degradation (AD) is very important in this regard, because fossil fuels can be substituted in power and heat production, used as feedstock for biochemical processing or transformed into fuel for vehicles (Weiland, 2010). Biogas is the product of the decomposition of different organic substances by a significant number of bacteria in the absence of oxygen (a process called anaerobic digestion). Methane gas is the main gas produced from the process, as well as carbon dioxide and hydrogen sulfide.
The sources of organic matter used in the production of biogas include food waste, animal waste and agricultural by-products. Anaerobic degradation of organic compounds can be efficient and stable when there is a balanced metabolism rate between the acid-forming bacteria and bacteria that form $\mathrm{CH} 4$ (Yu et al., 2003). Four major metabolic steps are involved in the entire anaerobic chains which are hydrolysis, acidogenesis, acetogenesis and methanogenesis. According to Solid Waste Corporation Management (SWCorp), 16,000 tons of food waste was generated by Malaysians daily in 2018. This amount is equivalent to feeding 12 million individuals three times a day. These wastes are also believed to be able to fill the 88 -storey Petronas Twin Towers to the brim in just a month or two if dumped in landfills. The food wastes dumped in the landfills 
would disintegrate and emit greenhouse gases, resulting in very significant negative impacts on the climate and contribute to global warming. Anaerobic waste and effluent digestion (AD) are a comprehensive process that is now effectively used in full-scale solid waste treatment and urban and industrial wastewater treatment systems (Cabezas et al., 2015). Furthermore, anaerobic digestion is considered as an active FW management strategy and provides many environmental benefits such as renewable energy generation and soil alteration production, alcohol, volatile fatty acids (VFAs) and other useful materials (Capson-Tojo et al., 2016).

In biogas digester, organic matter is generally a waste product, thus the reduction of the amount of food waste and other organic materials that are sent to landfill will minimize. Biogas is considered as environmentally friendly as it can be used in many different ways. irstly, it can be used as fuel for vehicles when compressed. Biogas can also be used for electricity generation or even refined and fed into the as grid on a commercial scale. Firstly, it can be used as fuel for vehicles when compressed. Biogas can also be used for electricity generation or even refined and fed into the as grid on a commercial scale. Futhermore, the benefit of biogas is it has zero net greenhouse emissions because when it burns, the $\mathrm{CO} 2$ released into the environment is no more than what was removed from the atmosphere when the organic matter was first produced (Alexander, 2018).

Nevertheless, gainingadeeperunderstanding of microbial communities and their role is therefore an important step towards improving anaerobic digestion's performance and system stability. This study analyzed the microbial characteristics under different $\mathrm{AD}$ conditions in order to establish the links between microbial community structure and operational condition efficiency.

\section{Materials and Methods}

\section{Substrates characterization}

Two types of food waste generated were collected for these experiments, which were leftover rice and vegetable wastes (VW). Then, physio-chemical characteristics of the collected samples were identified, of which included total solids (TS), volatile solids (VS) and Chemical Oxygen Demand (COD).

\section{Biochemical Methane Potential Test}

The BMP tests were performed using the batch system of a volume of $125 \mathrm{ml}$ serum bottle. The digestion is carried out in the mesophilic regime at $37^{\circ} \mathrm{C}$. Each bottle was partially filled with inoculum, the control substrate and added nutrient, then the volume of the digester was adjusted with distilled water to have the same test volumes. Then, the headspace was lushed with nitrogen gas. The experiment included food waste, which was the lefftover rice and vegetable waste for substrate tests and blank tests. All the tests were carried out in triplicate. Each bottle was sealed with a $5 \mathrm{~mm}$ thick silicone disc that was held tightly to the bottle head by a plastic screw cap punched in the middle. To enable gas transfer through the two connected bottles, the capillary tube was equipped on both ends with a needle, sharp enough to pierce the silicone disc. The BMP value was expressed in the volume of methane produced per gram of organic. The impact of the inoculum's origin on the methane yield in Biochemical Methane Potential (BMP) tests was investigated.

\section{Gas Chromatography}

To measure and separate different types of gases, gas chromatography was often used since gas chromatography equipment is the best option that could be used to analyze gases such as ethylene at low concentrations $(<1 \mathrm{ppm})$. From the BMP test, the serum bottle that had the highest biogas production was chosen and tested for and test for the composition of gas produced by using Gas-Liquid Chromatography (GLC) device.

\section{Pilot Plant Anaerobic Digester}

This experiment was conducted using pilotplant bio digester reactor. The pilot plant biodigester was monitored monitored for 43 days to identify the optimum level of COD removal efficiency. The COD removal efficiency was calculated from the COD concentration that had been tested three times a week during the monitoring period. 
The experiment was conducted with different amounts of substrate. Different amounts of leftover rice was used as a substrate, specifically $1.5 \mathrm{~kg}, 2 \mathrm{~kg}$ and $2.5 \mathrm{~kg}$.. Throughout the period, the reactor was operated for three times per week. A total of $50 \mathrm{ml}$ of digested sludge was collected for chemical oxygen demand test.

Chemical Oxygen Demand (COD) removal efficiency was used to determine the amount of organic matter in the anaerobic digestion process and identified the potential for biogas production. By using a strong chemical oxidizing agent, the oxygen equivalent of organic matter that can be oxidized was measured. During anaerobic digestion in the biodegradable COD present in the organic material, end products were preserved namely methane and the newly formed bacterial mass.

Besides, it was classified as the amount of given oxidant that reacts in controlled condition with the sample. Analysis of chemical oxygen demand (COD) was measured of the oxygen depletion potential from an organic waste contaminated water sample. The Chemical Oxygen Demand (COD) removal efficiency was used to determine the amount of organic matter in anaerobic digestion process and identified the potential for biogas production.

\section{Microbes Profiling}

Microbial data analysis has allowed researchers to understand better the phylogenetic and functional properties of microorganisms in order to establish the links between microbial community structure and operational condition efficiency.

To achieve an extensive understanding about the microbial characteristics, some methods must be developed such as DNA extraction. Firstly, samples were stored at $-20^{\circ}$ $\mathrm{C}$ until the extraction of DNA was carried out. Most of the extraction methods evaluated are straightforward methods (i.e. cells are lysed directly within the sample) with the exception of the EPI package, an indirect DNA extraction method (i.e. cells were extracted from the samples before cell lysis and DNA extraction) (Delmont et al., 2011). Macherey-Nagel NucleoSpin Soil Kit was used to extract DNA from the sample. The manual and protocol was mplemented to avoid DNA degradation.

DNA was then amplified so that it was replicated over several cycles to increase the number of copies of a specific target region exponentially and sequencing DNA where the 16S rRNA genes of the clones that have different RFLP patterns were sequenced by microbiology laboratory to identify their phylogenetic affiliation.

\section{Results and Discussion}

\section{Substrate Characterization}

Table 1 shows data characterization of the substrate that was used for this experiment which are leftover rice and vegetable waste. Substrate characterization included laboratory tests such as total solids (TS), volatile solids (VS), and chemical oxygen demand (COD) on the substrate.

Table 1: Data characterization of substrates

\begin{tabular}{ccc}
\hline Characterization & Rice & Vegetable waste \\
\hline Total Solid (TS) & $7.02 \%$ & $2.41 \%$ \\
Volatile Solid (VS) & $95 \%$ & $65 \%$ \\
Chemical Oxygen Demand (COD) & $17000 \mathrm{mg} / \mathrm{L}$ & $21000 \mathrm{mg} / \mathrm{L}$ \\
\hline
\end{tabular}

Based on the results, it can be seen that rice had the highest total solid and volatile solid compared to vegetable waste. Data also shows that vegetable waste had higher chemical oxygen demand compared to rice. Thus, it is proven that rice is the best substrate for the anaerobic digestion process. It is because highly volatile solids may lead to faster hydrolysis processes that lead to acidification and is good for methane production (Ji et al., 2017). 


\section{Biomethane Potential Test}

Cumulative bio-methane curves are the main results of the BMP tests as shown in Figure 1. The aim of the BMP test performed was to measure the potential of biogas produced from different substrates.

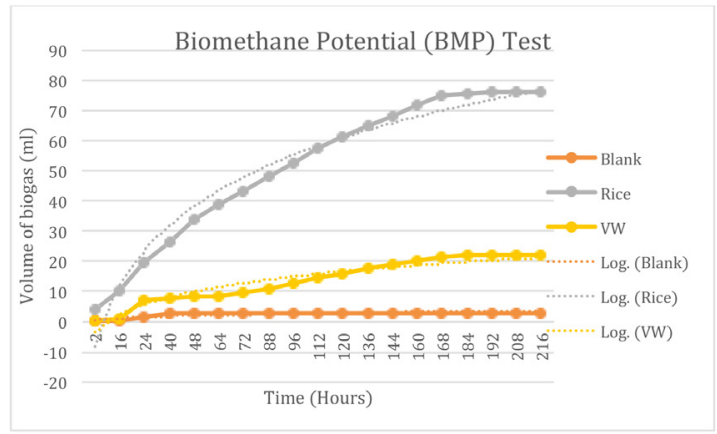

Figure 1: Biomethane potential test for different substrates

Based on Figure 1, the number of solids left decreases with time, as well as the rate of bio-methanation. The methane production was increased daily as the development of methane began in this phase of the study after 2 to 3 days after the reactors were put in the incubator. The biodegradation cycle takes time under mesophilic temperature to convert the end product in the form of biogas.

BMP test reveals that food waste under mesophilic condition has the highest efficiency compared to other conditions the other conditions. This indicates that rice is the best substrate indicates that rice consider as the best substrate for anaerobic digestion to produce biogas due to the fact that the carbon content in rice is higher than that found in vegetable waste due to carbon content in rice is higher compared to vegetable waste. According to (Gonzales et al., 2018), in anaerobic digestion, acetogenesis a complex process involving the transformation of organic acids with a number of carbons larger than two was required. Based on the results, it was shown that rice as the best substrate in producing biogas which is $76 \mathrm{~m}^{3}$.

\section{Gas Chromatography}

The aim of this study is to determine the amount of methane $\left(\mathrm{CH}_{4}\right)$ produced from the pilot plant bio-digester at optimum level. The content of methane and carbon dioxide are detected. Thus, the amount of methane gas is $69 \%$ and carbon dioxide is $31 \%$ indicating a stable anaerobic digestion process.

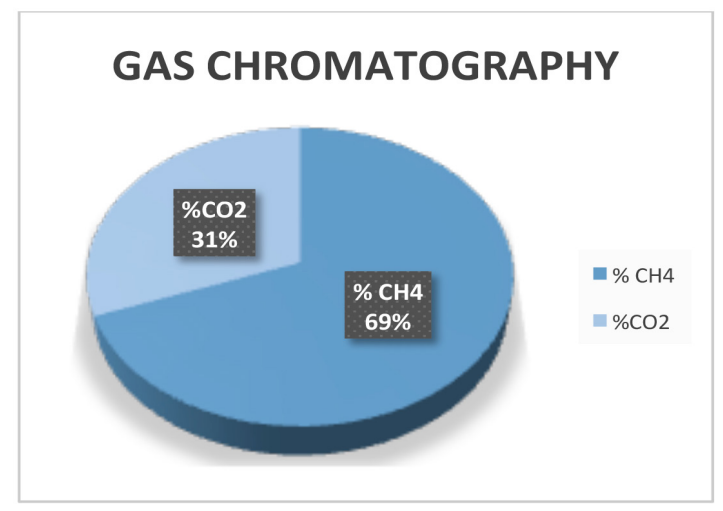

Figure 2: Gas chromatography of rice as substrate 


\section{COD Removal}

The results of the experiments show the performance of pilot plant bio-digester in the matter of chemical oxygen demand (COD) removal efficiency. The percentage COD removal was calculated using the Equation (1);
$\%$ COD Removal $=\left[\left(\mathrm{COD}_{(\mathrm{i})}-\mathrm{COD}_{(0)}\right) / \mathrm{COD}(\mathrm{i})\right] \times 100 \%$

Where $\operatorname{COD}(\mathrm{i})$ is the initial $\mathrm{COD}=$ concentration of substrate and COD (o) is COD concentration of effluent.

Table 2: Data for chemical oxygen demand

\begin{tabular}{cccc}
\hline Day & COD concentration $(\mathrm{mg} / \mathrm{L})$ & COD Removal Efficiency $(\%)$ & COD Feedstock (Rice) \\
\hline 0 & 32000 & $0 \%$ & 0 \\
1 & 64000 & $68 \%$ & 165333.33 \\
3 & 32000 & $86 \%$ & 165333.33 \\
5 & 26666.7 & $86 \%$ & 165333.33 \\
8 & 69333.33 & $64 \%$ & 165333.33 \\
10 & 37333.33 & $84 \%$ & 165333.33 \\
12 & 32000 & $84 \%$ & 165333.33 \\
15 & 21333.33 & $89 \%$ & 165333.33 \\
17 & 24000 & $87 \%$ & 165333.33 \\
19 & 24000 & $87 \%$ & 165333.33 \\
22 & 16000 & $93 \%$ & 220444.44 \\
24 & 58666.66 & $75 \%$ & 220444.44 \\
26 & 42666 & $85 \%$ & 220444.44 \\
29 & 21333.33 & $93 \%$ & 275555.55 \\
31 & 42666 & $86 \%$ & 275555.55 \\
33 & 21333.33 & $93 \%$ & 275555.55 \\
36 & 26666.67 & $91 \%$ & 275555.55 \\
38 & 37333.33 & $88 \%$ & 275555.55 \\
40 & 26666.67 & $91 \%$ & 275555.55 \\
43 & 21333.33 & $93 \%$ & 275555.55 \\
\hline & & &
\end{tabular}

Figure 3 shows the graph of pilot plant biodigester performance. Based on that figure, it shows the correlation of time (days) versus
COD concentration of digested sludge and COD removal efficiency. Digested sludge samples were collected three times per week for analyzing the amount of COD concentration. 


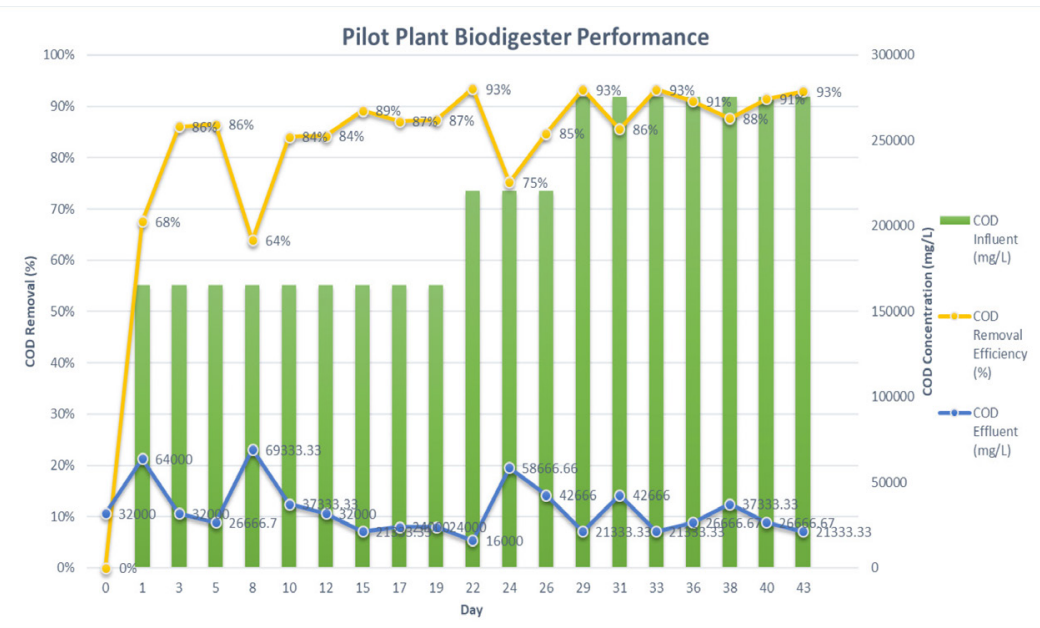

Figure 3: Pilot plant biodigester performances

Three phases were involved, namely initial, intermediate and final. The initial phase started at $0-19$ days with $1.5 \mathrm{~kg}$ of substrates with $165333.33 \mathrm{mg} / \mathrm{L}$ COD concentration fed into the bio digester. It showed the graph has slightly fluctuated and the COD removal efficiency was not at the optimum level. On day 8 , the COD removal efficiency reached its lowest point which was $64 \%$ with the highest amount of $69333.33 \mathrm{mg} / \mathrm{L}$ COD effluent.

At 22-26 days, the intermediate phase started with the feeding of $2 \mathrm{~kg}$ of substrates that contain $220444.44 \mathrm{mg} / \mathrm{L}$ COD concentration into the bio digester. Then, it was expected to achieve an optimum level of COD removal efficiency by increasing the quantity of substrate. However, the graph represents a decline with $75 \%$ of COD removal efficiency along with $58666.66 \mathrm{mg} / \mathrm{L}$ COD effluent.

Then, $2.5 \mathrm{~kg}$ of substrates which include $275555.55 \mathrm{mg} / \mathrm{L}$ COD concentration were fed into the biodigester for the final phase starting from 29 to 43 days. At this stage, the optimum level of COD removal efficiency had been achieved. In conclusion, the lowest amount of COD effluent, the highest COD removal efficiency.

The results showed the ranges of COD removal efficiency at an optimum level were $88 \%$
- 93\% which indicates a very high efficiency for the digester. It could be seen how the percentage COD (\%COD) reduction increased with HRT (days) until the 43 days when it assumed its maximum was $93 \%$. An optimum level of COD removal efficiency indicated active microbes' activities happen inside the bio digester.

\section{Microbes Profiling}

The digested sludge sample at optimum level of COD removal efficiency was used for microbial profiling. The physical state of the samples was brown color and liquid form. Based on Figure 3, the optimum level of COD removal efficiency indicated that active microbe activities had occurred inside the bio digester.

The samples were extracted using Macherey-Nagel NucleoSpin soil kit. The extraction were done at Biotechnology Laboratory of Aquatic Organism at the Institute of Tropical Aquaculture (AKUATROP) UMT. The extracted samples were sent to Apical Sdn Bhd for further DNA amplification and summary of microbial characteristics profiling at various states of anaerobic digestion is included in the Table 3.

The mechanism of anaerobic degradation involves a variety of different bacteria, but the process is driven mainly by two forms of reactions, acidogenesis and methanogenesis. 
Table 3: Microbial characteristics in anaerobic digestion stages

\begin{tabular}{lll}
\hline Anaerobic digestion Stages & Microbial characteristics & References \\
\hline Hydrolysis & Clostricdium, Bacteroides, Bifidobacterium, & (Wang et al., 2018) \\
& Butyrivibrio, & \\
Acidogenesis & Bacteroidetes, Chloroflexi, Firmicutes, and & \\
& Proteobacteria & \\
Acetogenesis & Pelotomaculum, Smithllela, and Syntrophobacter \\
Methanogenesis & Methanobacterium, Methanococcus, \\
& Methanothermobacter, Methanomicrobium, \\
& Methanosarcina, Methanosaeta, Methanobrevibacter, \\
& Methanospirillum and Methanoculleus & \\
\hline
\end{tabular}

\section{Conclusion}

In conclusion, the microbial characteristics of digested sludge from pilot plant biodigester performance at optimum level and the classification of microbes from digested sludge were determined. It can be concluded that pilot plant bio-digester can accommodate $3 \mathrm{~kg}$ food waste per time to produce biogas. The performance of biodigester at an optimum level of COD removal efficiency ranging between $88 \%-93 \%$ showing that there was a correlation between microbial community dynamics and anaerobic system stability. Therefore, monitoring anaerobic processes is important for optimizing the efficiency of reactors and preventing potential system failures.

The efficiency and stability of the digestion process depend heavily on a number of different microbial classes, and substrate characteristic and operating parameters affect their systems and functions. Besides, it is essential to improve understanding of microbial community structure and their functions throughout the anaerobic digestion process.

Lastly, this study showed that food waste or specifically rice was the best substrate for anaerobic digestion based on observation on the volume of biogas produces and methane composition as well as the characterization of the substrate.

\section{Acknowledgements}

Thank you to my supervisor and Universiti Malaysia Terengganu.

\section{References}

Alexander, S. (2018). Home biogas: turning food waste into renewable energy. Retrieved 20 December 2019, from https://theconversation.com/home-biogasturning-food-waste-intorenewableenergy-89920.

Cabezas, A., de Araujo, J. C., Callejas, C., Galès, A., Hamelin, J., Marone, A., $\&$ Etchebehere, C. (2015). How to use molecular biology tools for the study of the anaerobic digestion process? Reviews in Environmental Science and Biotechnology, 14(4), 555-593.

Capson-Tojo, G., Rouez, M., Crest, M., Steyer, J., Delgenès, J., \& Escudié, R. (2016). Food waste valorization via anaerobic processes: a review. Environ. Sci. Biotechnol, 15, 499-547.

Delmont, T. O., Robe, P., Clark I., \& Simonet, P. V. T. (2011). Metagenomic comparison of direct and indirect soil DNA extraction approaches. J Microbiol Methods, 86(3), 397-400

Ji, C., Kong, C. X., Mei, Z. L., \& Li, J. (2017). A Review of the Anaerobic Digestion of Fruit and Vegetable Waste. Applied Biochemistry and Biotechnology, 183(3), 906-922. https://doi.org/10.1007/s12010-0172472-x 
González, J., Sánchez, M., \& Gómez, X. (2018). Weiland, P. (2010). Biogas production: Current Enhancing Anaerobic Digestion: The Effect of Carbon Conductive Materials. C, 4(4), 59. https://doi.org/10.3390/c4040059

Wang, P., Wang, H., Qiu, Y., Ren, L., \& Jiang, state and perspective. Applied Microbiology and Biotechnology., 85, 849-860.

B. (2018). Microbial characteristics Yu, H. Q., \& Fang, H. H. P. (2003). Acidogenesis og Gelatin - Rich Wastewater in an Upflow Anaerobic Reaktor:Influence of in anaerobic digestion process of food waste for methane production-A review. Bioresource Technology, 248, 29-36. $\mathrm{pH}$ and Temperature. Water Research, 37(1), 55-56 